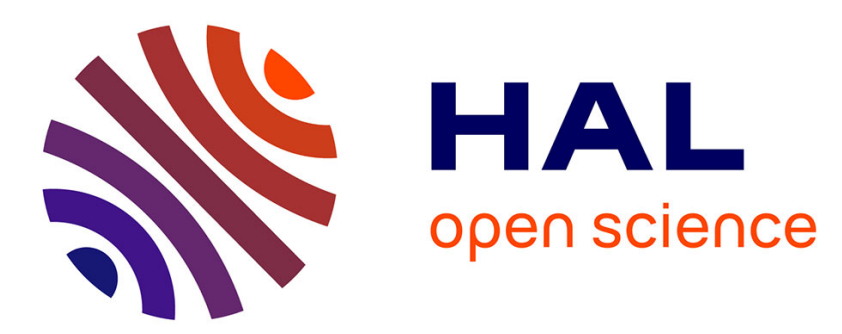

\title{
Consequences of the declining interest in computer science studies in Europe
}

\author{
Katherine Maillet, Marcela Porta
}

\section{To cite this version:}

Katherine Maillet, Marcela Porta. Consequences of the declining interest in computer science studies in Europe. EDUCON 2010: IEEE Engineering Education 2010: The Future of Global Learning in Engineering Education, Apr 2010, Madrid, Spain. pp.71 -, 10.1109/EDUCON.2010.5492597 . hal02444253

\section{HAL Id: hal-02444253 \\ https://hal.science/hal-02444253}

Submitted on 17 Jan 2020

HAL is a multi-disciplinary open access archive for the deposit and dissemination of scientific research documents, whether they are published or not. The documents may come from teaching and research institutions in France or abroad, or from public or private research centers.
L'archive ouverte pluridisciplinaire HAL, est destinée au dépôt et à la diffusion de documents scientifiques de niveau recherche, publiés ou non, émanant des établissements d'enseignement et de recherche français ou étrangers, des laboratoires publics ou privés. 


\title{
Consequences of the Declining Interest in Computer Science Studies in Europe
}

\author{
Katherine Maillet, Marcela Porta \\ Departement des Langues et Sciences Humains \\ Telecom \& Management SudParis \\ Evry - Val - d'Essonne, France
}

\begin{abstract}
Official European statistics of education indicate that the number of students entering tertiary education have significantly increased between 2000 and 2006 [1], and indicate a trend that will continue. However, this increase is not reflected in every field of study; computer science and engineering are among those that have decreased each year, evidence of a decline of interest in following this career on the part of students. As a response to this disturbing fact, this paper aims to identify some of the possible consequences that this trend could produce in Europe. It will highlight the impacts in economic, social, political and pedagogical fields and explain how these segments will be affected if the decline in computer science persists. Supported by previous investigations and official reports, this analysis provides some examples of the problems already produced by the declining interest in computer science in Europe and proposes solutions such as teaching methods and learning strategies to attract more students to this field and therefore limit the negative effects in a near future.
\end{abstract}

Keywords-component; Computer Science studies, learning methods, teaching methods

\section{INTRODUCTION}

The official European statistics reflected a low rate in the number of high school students choosing computer science as a career. While the number of students entering university is rising, this field of study represents just $9.9 \%$ and decreases each year [1].

Because of this, European countries might be affected by a low number of experts in technology that represents an important stake for industry. In France for example, people spent a total of 7,965 millions of Euros in technology in 2008 [18].

The relationship between the high demand of technology and the decreasing number of experts to support it, leads us to ask the following questions:

- How can Europe justify the decreasing interest in computer science studies when the demand from the technological industries remains stable?

- What are the main reasons that produce this decline in the choice of computer science as a domain of study?

- Is it important for Europe to promote Engineering school?
- What are the consequences of a reduced number of computer science experts in industry and research in Europe?

This paper aims to demonstrate the imbalance between the number of students choosing computer science as a domain of study in relation to the demand in the industry and points out the importance of attracting and retaining students to this field by highlighting the possible consequences that this decrease could produce in different sectors.

As a conclusion, this document will point to some solutions that could be used in order to bring alternatives to these issues and prevent the negative impacts.

\section{RELATED WORK}

Certain studies are investigating related questions about the number of students enrolled in technology. Some of these studies highlight the fact of the low interest in computer science as part of their results.

In 2009 the Computing Research Association (CRA) remark that the number of undergraduate students majoring in computer science significantly increased [2]. This fact not only creates a concern about the future of technology in Europe, but also sustains the decline of interest in computer science.

A larger investigation by Mahar, J. [3] was dedicated to find strategies to attract women to computer science, expressing their concern about the low number of them in this scientific field. In 2008, the proportion of women opting for scientific and technological studies was lower than the $40 \%$ in Europe, concerning computer science as a part of the study [4].

These references affirm that investigating the reasons of this decline is essential in order to understand and control this problem. Some studies agree that the reason why a student does not pick computer science or does not feel attracted by technology as a domain of study is related to the image these careers reflect or to the degree of difficulty that these domains seems to represent: in 2006, a European orientation study suggested that "The choice of the students is essentially determined because of the image of the professors in the scientific and technological areas and by the content and quality in the discipline" [4]. 
Academics thought that vague and erroneous perception begins in high school and that industry could do more to improve the image of jobs and careers in this domain and help identifying a stereotype that has not been clearly identified yet [5].

Nowadays, the real reasons that produce the rejection of computer science as a domain of study is not yet discovered. However, the importance in the number of technology professionals in Europe is determined by the possible consequences that can take place if this decline is not controlled and this is what this paper will emphasize.

\section{POPULATION RESULTS AND EDUCATION KEY STATISTICS IN EUROPE}

The official key statistics in Europe, delivered the results of the educational analysis in the European countries [1].

This study leads to understand the declining performance of computer science school in Europe and enclose general conclusions to better understand the importance on the evolution of this field and its consequences in case of failure.

\section{A. Education Statistics for Europe 2000-2006}

The statistics published in 2008 [1], indicated that the number of students that have access to tertiary education in
Europe is increasing in a sustainable way. In other words, the number of students attending university after high school is rising as shown in Figure 1.

Unfortunately the increase in tertiary studies is not reflected in all domains of study. Graduates in science, mathematics and computing have decreased each year as shown in Figure 2 [1], reflecting the lack of motivation of following scientific careers from the part of students.

While analyzing the computer science results it is important to highlight two main concerns:

- Graduates in computer science and engineering are decreasing; while graduates from other fields of study are increasing or remain stable.

- We can presume that there are specific reasons which cause students to reject science, math, computing, manufacturing and engineering.

The declining interest in computer science education surprise the more when they come from developed countries in which an important part of their industries depend on the evolution of technology and constitute a significant change affecting labor demand [19].

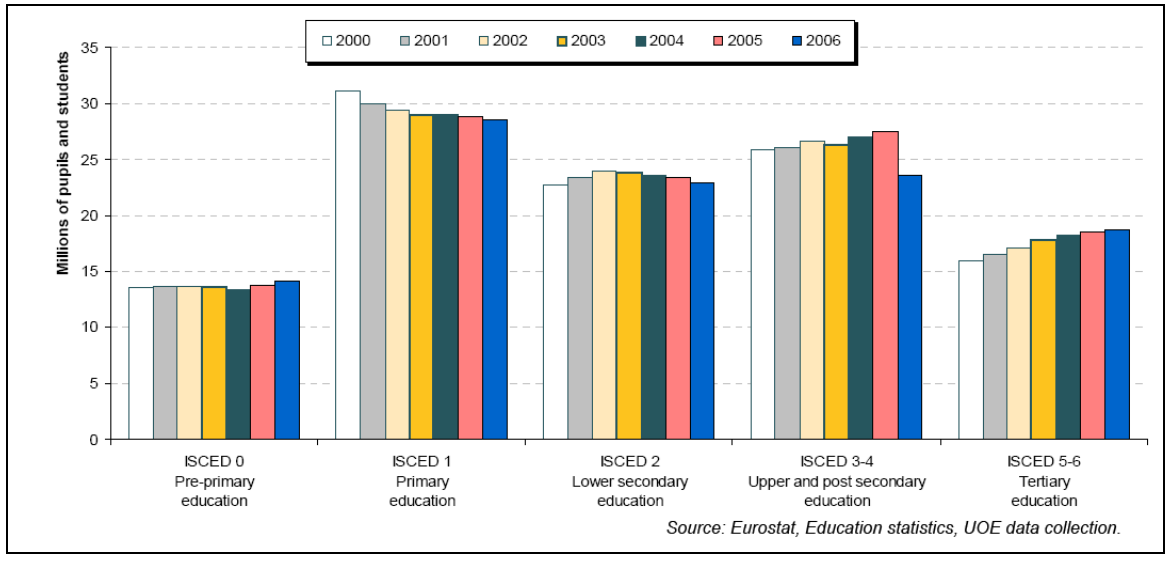

Figure 1. Distribution of tertiary graduates by field of education, EU27, 2000 and 2006, in \% 


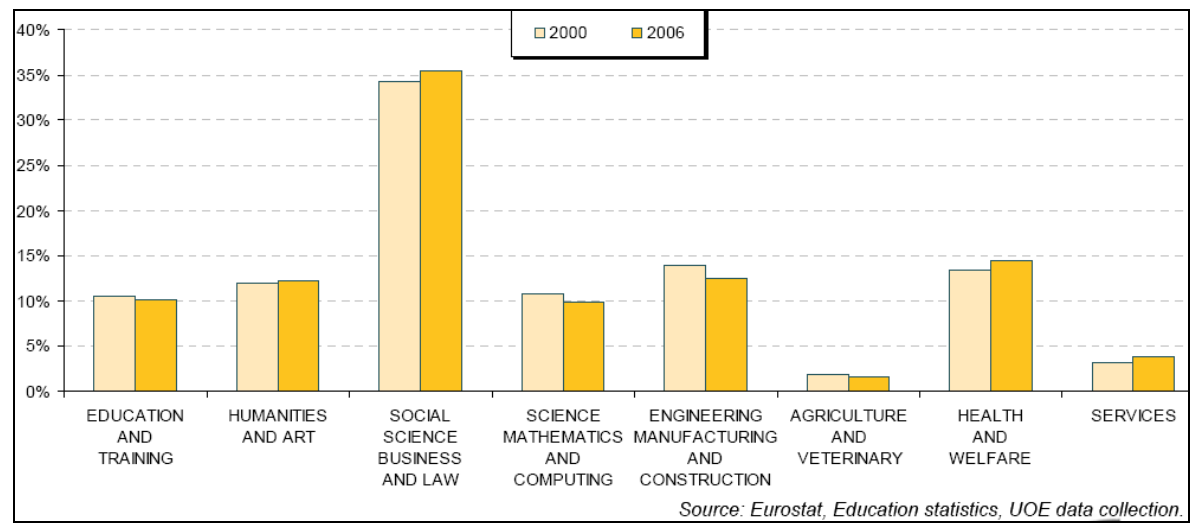

Figure 2. Number of pupils and students by level of education (in millions), EU27, 2000 to 2006

There are other analyses that reflect and confirm the declining interest in computer science, such as the one shown in Figure 3, provided by the Computer Research Policy Association [18]. It illustrates the continuous decrease in computer engineering and computer science graduates from 2001 to 2005 .

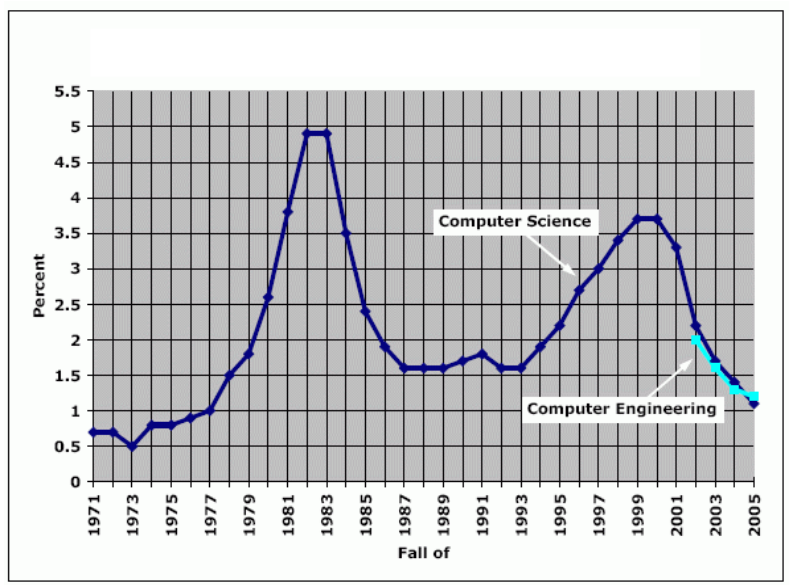

Figure 3. Development of computer engineering and computer science in persentage of university graduates during the last years

These statistics lead us to agree in the fact that the interest in computer science is declining and that this decline may alter and bring consequences in the technological field for European countries.

\section{B. Analysis and enclose of the situation}

The latest statistics show a reduction in the number of persons studying computer science in university. This decrease represents, as general consequence, the declining number of professionals in this field and thus involved in the development of local technology in Europe.

Other sectors such as the economic, social, political and pedagogical fields will reflect similar consequences. The next section will present the possible impacts of the declining interest in computer science studies in Europe.

\section{CONSEQUENCES OF THE DECLINING INTEREST IN COMPUTER SCIENCE STUDIES IN EUROPE}

\section{A. Economic consequences}

1) A reduction in the number of computer science students will result in a decreaing number of experts in the technology field in the near future

In general, when the stakes of an industry are reduced in number of experts, it will cause an increase in the price of the good or service that these experts provide. The economic model on elasticity shows a comparison between the market price of a product or service and the offer of the same, i.e. less human force with the same demand is equal to a price increase.

The price $\mathrm{P}$ of a product is determined by a balance between productions at each price or supply $\mathrm{S}$ and the desires of those with purchasing power at each price or demand D. Along with a consequent increase in price and the quantity sold of the product [6]. This theory is quickly highlighted in Figure 4.

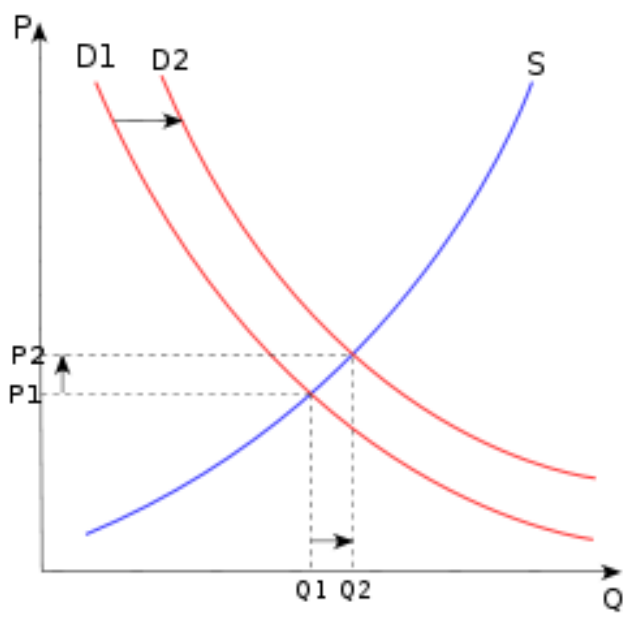

Figure 4. Elasticity of the price of a product 
Explained from this point of view the number of students and experts in the technological field is crucial to balance prices and promote the progress of the nation's technology industry, because a low offer in the market of technology represent a more expensive product.

This increase in the price of computing development and the decrease of professionals in the industry can be related to the initiative of the companies that redirect or migrate their labor forces to foreign countries where development is not only as efficient as in Europe, but also where there is a greater available production capacity at a lower cost, e.g. India.

2) A migration in the labor force and technological development to foreign countries

The migration of the technology from a company that can not afford development in its own country is very common these days. Countries will buy the software and programs to other countries willing to maintain the low prices in operative costs.

This fact represents a great opportunity of development for those countries trusting technology as a development strategy. However, a negative impact will take place in the purchasing countries, because this migration can turn out in instability of the industry, due to: the migration of the human force and abolition of actual and future jobs, the reduction in local tax payment and most important, the absent of strategies to manage this impact.

Because of this, predictions of job losses from shifting high-technology work to low-wage nations with strong education systems, like India and China, were greatly exaggerated. As remarked by Lohr, S. 2006, "The concern is that misplaced pessimism will deter bright young people from pursuing careers in computing, and, in turn, would erode the skills in a field that is crucial to the nation's economic competitiveness" [7].

\section{B. Social consequences}

1) Increase in careers outside math, science, computing, manufacturing and engineering

As we previously understood, the number of university students is rising. This fact also suggests that university students that are not choosing technology as a career are selecting another one. As shown in the previous graphs, careers like business and social science are the ones increasing the most these days [1].

This fact can be related to an increase in the job opportunity needed for negotiating and purchasing technology from other countries. The global increase on the technology demand produces success in management careers such as purchasing and international commerce because the technology that is not being developed in Europe is being purchased from other countries.

This tendency will result in a higher proportion of professionals trained to be managers and businessmen and a lower number of engineers and producers of technology; which is not precisely a negative change, but represents an alteration that needs to be assumed.

\section{2) The need to learn other cultures and languages}

Due to the migration of the human resources, there is an increasing need to learn other cultures and languages to succeed in negotiations with other countries.

Nowadays a person speaking several languages has a large number of job offers in Europe thanks to the companies that need interlocutors for their commercial exchanges.

However, the culture and languages of the countries which are involved in technology development are not precisely related to the European. Therefore, Europeans might loose their strengths of speaking English, French and Spanish (more speak languages in Europe and in the world) and became weak when facing the opportunities that are presented to Chinese, Russian and other languages speaking countries [8].

Following this example, we may find a certain number of investigations considering the importance of integrating foreign languages and cultures to European countries, not only in the name of technology development, but also because unique educational modules, courses and programs are being designed and evaluated throughout the Asian region, evidencing issues, challenges, opportunities and initiatives related to the education of technology. [20]

One of the solutions could be to include these languages in the curricula offered to students seeking careers in business. This will permit students to gain opportunities in international job offers and be prepared to affront their professional lives after university. Some studies emphasize the importance of learning other languages to meet this demand and to adopt the economic change that Europe might be affronting [9].

Unfortunately taking as an example the program of study offered to students of one of the most popular careers (economics and management) at one of the best universities in Europe, we can see that the language options are limited to Europeans and neither Chinese nor Japanese, or other language that represent geographical expansion is offered as shown in Figure 5 [10].

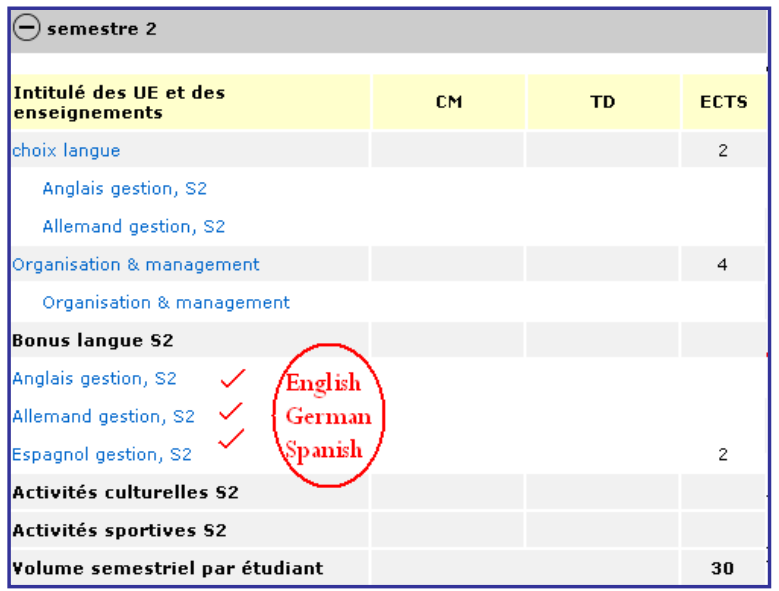

Figure 5. Sorbonne University, $2^{\text {nd }}$ semester Management Curricula 
However in its many international exchanges, European universities are providing educational programs to foreigners, giving them the expertise and knowledge of the European market and enhancing the population that in some years will represent the strongest competition for local professionals.

This fact can be demonstrated by an example: In France the number of Asian students has tripled in five years; as published in its annual report on diplomacy in 2006.

Thus Asians represent the fastest growing group of foreign students highly incentive form the French government [11], however this document specifies as well that only $5 \%$ of these foreign students stay in France, while the rest of them return to their countries to work in the field contributing to the migration of the technology development.

By the other hand, the countries producing technology can appreciate a fast progress observed from a positive point of view. Some countries might find in this the occasion to expand their industries and create links with other cultures that will represent an economic profit for them.

\section{Political consequences}

\section{1) General dissatisfaction causing political instability}

The lack of opportunities in a country for a person that has concluded secondary studies can represent a menace to the economy and the stability of the country itself. The information about companies that migrates the development of technology out of Europe might guide us to ask ourselves about the future of thus professionals that might lose their opportunities to work.

Europe is already subject to several aggressive strikes that reflect the dissatisfaction of the local workers due to the migration of the labor force to other countries which is affecting their careers.

For example, the employees of JLG Industries, the world's leading designer, manufacturer and marketer of access equipment, went on strike as a result of a possible delocalization of the labor force. The employees threatened to explode the warehouse if the company did not stop the policy of firing a certain number of people at the end of the year [12].

Another related event was a demonstration organized by students of informatics engineering and other careers related to computer science, who manifested their concern about the lack of job opportunities in the field in Europe [13].

These demonstrations create an environment of insecurity, violence and material damages in Europe that can also harm political image.

\section{2) Modifications in the national curricula}

The political influences on education have been rapidly increasing over the past several decades. Recently, the power of the state has been expanding further into the domain of the university. Any curricular changes in teacher education must be planned with an eye toward the state's expected role. This may be the most crucial aspect of technology integration.

Curriculum developers may not be well versed in governmental matters and may have to change the ways they prepare for reform while facing changes in things such as: the budget, the importance to foreign languages and cultures and the political instability. [21]

\section{Pedagogic consequences}

\section{1) Declining careers in engineering}

If the number of graduates in a specific subject is reduced or simply modified, there will be a similar reduction or modification in the number of professors in this discipline. Therefore, the difficulty to find teachers that provide students the knowledge and expertise to develop technology will increase.

The success of computer science is based on the number of experts involved in the same geographic area, the entire development of technology depends on the persons who have the expertise to create and maintain technology because they are capable to create and maintain technology material.

\section{2) Declining investment in the field of study}

The fact of reducing the number of computer science students might represent less founds for the development of this educational sector, because institutions in charge of providing money to education will not invest in a career without students. As a catastrophic result this could eventually mean the complete elimination of this career in Europe.

One example of this fact is reflected in the European Commission that will sponsor a large number of contracts directed to technology research in order to the results that the partners conforming this contracts could offer, i.e. the number of publications in collaboration with students and professors. Therefore, with no experts working in the development of technology research, the funds coming from the European Union might be reduced.

\section{CONCLUSIONS AND FUTURE WORK}

After analyzing the consequences of the declining interest in computer science in Europe, two main conclusions can be appreciated:

\section{A. Increase the number of computer scientist in Europe}

The first conclusion refers to the fact that in order to maintain the development of computer science as a career and as the basis of technology in Europe it is necessary to attract and retain human talent in this field.

As a strategy to this matter, a future work can be directed to identify the reasons why a student does not feel the motivation to follow computer science studies as a career and to create methods that attract and retain people in this domain of study. 
As mentioned previously, some studies blame the negative image this career reflects while observing the professionals working in this field [5].

Other analysis demonstrate that preventing young students from using technology in an early age might psychologically affect a child and cause him to reject this discipline his entire life. Parents forbid children to touch expensive equipment (that could be attractive to them in the first place), such as computers and televisions etc. and give them the wrong impression of being incapable to operate them and impede the development of their technological skills [16].

Other programs have directed their strategies to attract women to these scientific domains. The development of such strategies has made it possible to attract undergraduate students historically not enrolled in computing courses and therefore attract students to this field [15].

\section{B. Adopting the changes that computer science is affronting}

As specified before, a general recommendation to adopt the technological raising in other countries is necessary. The fact of learning other languages, expanding markets and modifying teaching/learning curricula was mentioned as a technique to affront the consequences of the migration of computer science and gain advantages in the international market.

Other initiatives have already launched strategies targeting a more specific area; they create teaching and learning methods to enhance e-learning and support students with the help of information technologies such as "Effective video clips for Web-based language learning" [14]. This study affirms that the opportunity of providing new technological features to existing teaching methods will help attracting users and students to the technological field.

\section{BIBLIOGRAPHY}

[1] Eurostat, 2000 - 2006. Official European Statistics.

[2] Computing research policy, 2009. Advocacy and Policy Analysis for the Computing Research Community. http://www.cra.org/govaffairs/blog/archives/000729.html

[3] Mahar, J. 2008. Virtual Outreach through virtual worlds: a model for attracting and keeping women in computing. ACCE Elearn conference.

[4] OCDE, 2006. Evolution of the joung interest fot the scientific and technological studies - Évolution de l'intérêt des jeunes pour les études scientifiques et technologiques. Rapport d'orientation. Paris, France.

[5] T. Koppi and AL. 2008. The crisis in ICT education: An academic perspective, Proceedings ascilite Melbourne, 505-508.

[6] Henderson, Hubert D. 1946. Supply and demand: The theory of elasticity in price. Hancourt Editorial.

[7] Lohr, S. 2006. Study Plays Down Export of Computer Jobs. New York Times Harvard Business Review, USA.

[8] Williams, A. July 22, 2009. Lessons in Mandarin Chinese-language immersion school near reality in Eugene. New York, USA.

[9] Zimmermann, B.J. 1986. Development of self-regulated learning: Which are the key sub-processes? Contemporary Educational Psychology, 16, $307-313$

[10] Curricula report university of Sorbonne Paris 1. 2nd year Economy and Management. Contenu du second année du management, Université Sorbonne Paris 1; Frace, 2009.

[11] French official report from diplomacy, 2009. http://www.diplomatie.gouv.fr/en/france 159/label-france 2554/label-france-issues 2555/label- france-no.-62_3407/feature-studying-the-french-way_3410/asia-rapidly-expanding-cooperation $4245 . \mathrm{html}$

[12] Raffine, O. The social conflicts sign of fragility on the syndicates. - La radicalisation des conflits sociaux signe de fragilité des syndicats. 20 Minutes Journal, France, 2009..

[13] ABC News,. Informatic engineers sticke.- Ingenieros informáticos se plantean. Madrid, España. February 2009.

[14] Kobayashi, T. and AL, 2008. Effective Video Clips for Web-based Language Learning. ACCE Elearn conference.

[15] Madison, S. and AL, 2008. Project Focal Point: Attracting females to the computing sciences. ACCE Elearn conference.

[16] Pedersen, S. 2007. Child development, the timing of middle childhood. Science daily, university of Oslo.

[17] Computing research policy, 2009. Advocacy and Policy Analysis for the Computing Research Community. http://www.cre.org/govaffairs/blog/archives/000729.html

[18] Statistique Study, 2008. "Les chiffres clés d'Avril 2008”. Republique Francais.

[19] Timothy F. Bresnahan, Stanford University; Erik Brynjolfsson, Sloan School of Management, Massachusetts Institute of Technology; Lorin M. Hitt, Wharton School, University of Pennsylvania. 2002. Information Technology, Workplace Organization, and the Demand for Skilled Labor. Quarterly Journal of Economics, Vol. 117, No. 1, Pages 339-376

[20] Bonk, C.J., Lee, M.M. \& Reynolds, T. (Eds.). 2009. A Special Passage Through Asia E-Learning. AACE conference.

[21] Rock, T. \& Passe, J. (2004). An Analysis of an Elementary Social Studies Methods Course. AACE 313-322. 